\title{
Antegrade transcatheter closure of coronary artery fistulae using vascular occlusion devices
}

\author{
C A C Pedra, J Pihkala, D G Nykanen, L N Benson
}

\begin{abstract}
Two children (a 9 year old boy and a 2.5 year old girl) with coronary artery fistulae communicating with the right ventricle underwent successful transcatheter occlusion using an antegrade technique. A Rashkind double umbrella device was used in one case and an Amplatzer duct occluder in the other.

(Heart 2000;83:94-96)
\end{abstract}

Keywords: interventional cardiology; congenital heart defects; coronary artery fistula; paediatric cardiology

Coronary artery fistulae are uncommon heart lesions, but they are the most frequent significant haemodynamic congenital coronary anomaly. ${ }^{1}$ Large fistulae generally require closure to prevent complications such as myocardial ischaemia from a steal phenomenon, endocarditis, and potential aneurysmal dilatation and rupture. ${ }^{2}$ There have been many reports describing catheter based treatments as options in the management of this disorder. ${ }^{3-6}$ We report two cases in which uncommon transcatheter approaches were used to close such fistulae arising from the right coronary artery.

\section{Case 1}

A 9 year old boy was referred to our unit with a diagnosis of a coronary artery fistula. The patient was asymptomatic and physical examination was notable for a grade $3 / 6$ continuous murmur heard at the left lower sternal border. The resting ECG and chest radiograph were normal. Echocardiography showed a mildly dilated left ventricle. A fistula was seen by colour Doppler arising from a dilated right coronary artery (RCA) and draining into the right ventricle beneath the septal leaflet of the tricuspid valve. After informed consent, the patient was taken to the cardiac catheterisation laboratory for attempted occlusion.

Under general anaesthesia the femoral artery and vein were cannulated and the patient heparinised. Cefazolin was administered at a dosage of $40 \mathrm{mg} / \mathrm{kg}$. Left and right heart haemodynamics were within the normal limits. Aortography and selective coronary angiography revealed a dilated RCA (measuring $8 \mathrm{~mm}$ ) and a coronary fistula originating from the distal portion of the RCA emptying in the right ventricle beneath the septal leaflet of the tricuspid valve (fig 1) measuring $2.5 \mathrm{~mm}$ in diameter and $5 \mathrm{~mm}$ long. Coronary artery branches supplying the interventricular septum and the inferior left ventricular wall were noted to arise close to the origin of the fistula at the crux of the heart. After a selective injection into the distal RCA, an episode of ventricular fibrillation occurred requiring defibrillation. After haemodynamic stabilisation, a $5 \mathrm{~F}$ right coronary artery catheter (Judkins; Cook, Bloomington, Indiana, USA) was advanced distally into the fistula over a 0.014 inch coronary guide wire (Wizdom; Cordis Corp, Miami, Florida, USA). A Cook detachable coil (5 mm diameter, five loops) was released in the fistula but embolised into the right ventricle. No attempt was made to retrieve the coil as it was within the tricuspid valve chordal apparatus and in a stable position. A right coronary catheter was again advanced to the fistula and a 0.035 inch exchange $(260 \mathrm{~cm})$ guide wire (Cook) was passed through this catheter and snared in the right ventricle (Microvena; Vadnais, Minnesota, USA). The exchange wire was exteriorised out the femoral vein forming an arteriovenous wire loop. A hand shaped $7 \mathrm{~F}$ sheath and dilator (Cook) were then advanced over the exchange wire from the femoral vein and positioned within the right ventricular mouth of the fistula. The dilator was removed and a $12 \mathrm{~mm}$ Rashkind umbrella (USCI Angiographics; CR Bard, Bellerica, Massachusetts, USA) was advanced through the sheath using the front loading technique. ${ }^{7}$ Repeat contrast injections in the RCA allowed visualisation of the device with the distal arms opened in the fistula, away from the distal coronary branches. After deployment, the device remained in a stable position and further RCA angiography showed complete closure of the defect as well as improved filling of the distal coronary branches (fig 1). Echocardiography performed during catheterisation after coil embolisation revealed trivial tricuspid regurgitation and no evidence of tricuspid stenosis. The child was observed overnight having no arrhythmias and discharged home the following day. A chest radiograph showed that the embolised coil was in a stable position within the right ventricle.

\section{Case 2}

A 2.5 year old girl was referred to our hospital because of a coronary artery fistula. Failing to thrive (weight $9.5 \mathrm{~kg}$, below the fifth centile), 

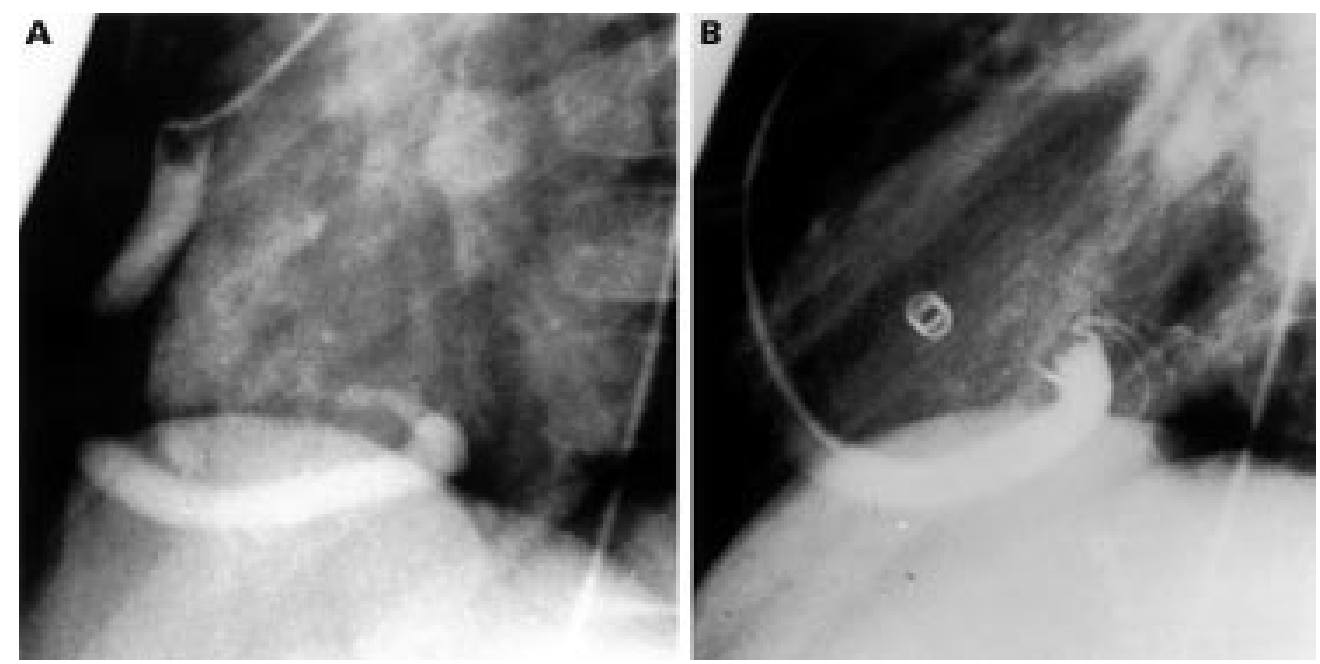

Figure 1 (A) Lateral projection of a selective injection into the right coronary artery fistula draining into the right ventricle near the tricuspid valve (case 1). (B) Same projection, after double umbrella placement, a distal injection into the right coronary artery defines improved flow to distal coronary artery branches and complete fistula closure. Note embolised coil in the right ventricle.

physical examination was notable for a grade $4 / 6$ continuous murmur heard at the left lower sternal border. Chest radiography revealed mild cardiomegaly and increased pulmonary vascularity, and an ECG showed left ventricular hypertrophy. Colour Doppler echocardiography showed a large coronary fistula arising from the proximal third of the RCA draining into the posterior aspect of the right atrium and a dilated left ventricle. After informed consent, left and right heart catheterisation were performed under general anaesthesia.

The patient was heparinised (150 IU/kg) and cefazolin given at a dosage of $40 \mathrm{mg} / \mathrm{kg}$. Aortic pressure was $80 / 35 \mathrm{~mm} \mathrm{Hg}$ (mean $58 \mathrm{~mm} \mathrm{Hg}$ ). Aortography and selective coronary angiography revealed a dilated RCA (measuring $8 \mathrm{~mm}$ proximally) and a long, tortuous coronary fistula arising from the initial third of the RCA, proximal to the origin of the first preventricular coronary branches. The fistula had a posterior course (fig 2) with two aneurysmal dilatations emptying into the right atrium with two narrow exit sites. The proximal curved portion of the fistula
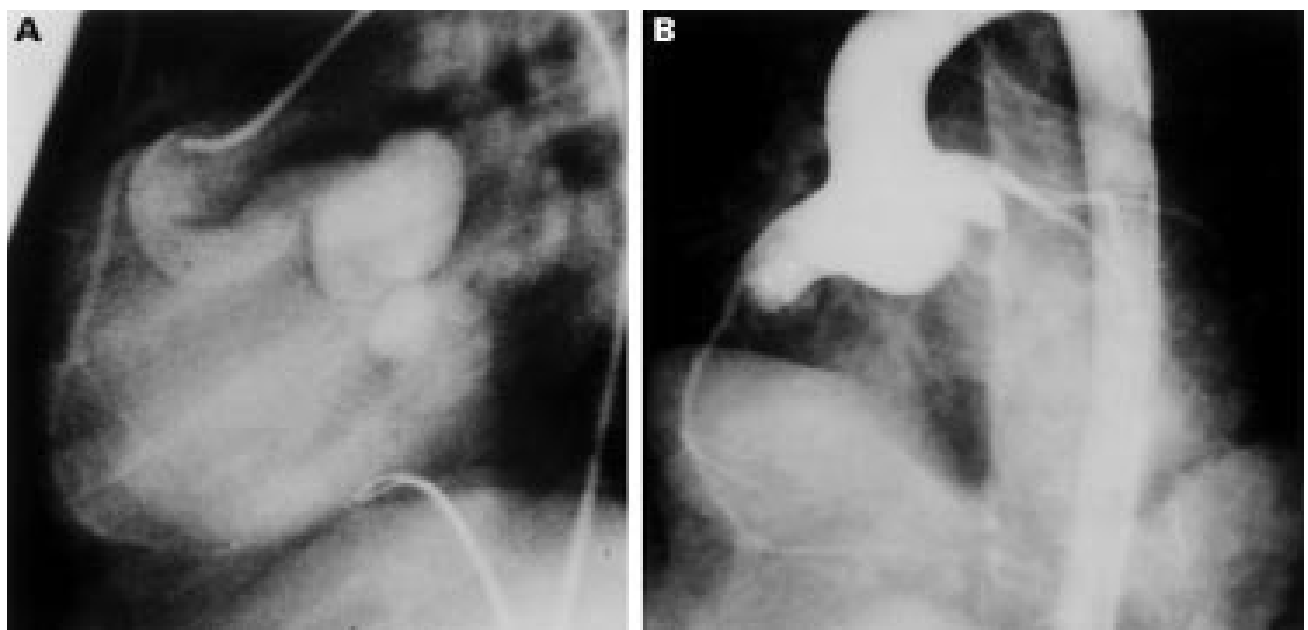

Figure 2 (A) Lateral projection of a selective coronary injection into the right coronary artery of case 2 defining a large, tortuous fistula draining into the right atrium. (B) After device implantation, an aortogram defines complete fistula occlusion. measured $6 \mathrm{~mm}$, the first pouch $17 \mathrm{~mm}$ and the second $11 \mathrm{~mm}$. A $5 \mathrm{~F}$ right coronary artery catheter (Cook) was advanced into the RCA with a preload coaxial system consisting of a 0.014 inch coronary guide wire (Wizdom; Cordis) passed through a $3 \mathrm{~F}$ coaxial injectable catheter (Baylis Medical Company Inc, Montreal, Canada). The coronary wire was manoeuvred through the fistula and the system was snared in the right atrium using a gooseneck snare catheter (Microvena). The retrograde right coronary catheter was exteriorised out the femoral vein. The wire and the coaxial catheter were then replaced with an exchange $(260 \mathrm{~cm}) 0.035$ inch wire (Cook). From the femoral vein and over this wire, a hand shaped $6 \mathrm{~F}$ long sheath was advanced to the ascending aorta using a $6 \mathrm{~F}$ Gensini catheter (USCI Angiographics) as a dilator. Repeat angiography through this catheter further delineated the complete anatomy of the fistula.

The wire and the Gensini catheter were removed and an Amplatzer duct occluder (10$8 \mathrm{~mm}$; AGA Medical Corp, Golden Valley, 
Minnesota, USA) was loaded and passed through the sheath. The whole system was positioned at the proximal third of the fistula close to origin of the RCA and the device delivered according to previous published techniques. ${ }^{8-10}$ Retrograde selective right coronary injections helped to position the device. No ECG changes were noted and after 10 minutes the device was released. Repeat angiography showed complete closure of the fistula with no flow compromise to the RCA (fig 2). The following day transthoracic colour Doppler echocardiography showed that the device was well positioned within the fistula with no residual flow. The patient was discharged home on low dose aspirin.

\section{Discussion}

Many authors have described transcatheter closure of congenital coronary fistulae using a variety of techniques and devices..$^{3-6}$ Nevertheless, there are few reports addressing the use of the Rashkind double umbrella or the Amplatzer septal occluder for this purpose. ${ }^{4}$ The choice of device and technique is based on many factors including cost, familiarity of the operator with the different approaches, and most importantly on the anatomic characteristics of the fistula. ${ }^{3}$

In our case 1, the fistula was relatively narrow, straight, and short with important coronary branches arising close to the fistula's right ventricle ostium. These features led to a failed coil implantation as the location of the coronary branches required the coil to be released distally and the fistula was not long enough to accommodate the coil in position. Although the Rashkind double umbrella has not been used frequently to close congenital coronary fistulae, the anatomical pattern described in this case was particularly suitable for umbrella placement. ${ }^{4}$

From a practical standpoint, certain technical requirements for umbrella implantation in the fistula are worth mentioning. Pre-shaping of the sheath (using a heat gun) along the curvature from right atrium to right ventricle and fistula was important to prevent sheath kinking, and front loading of the device allowed a smooth progression of the implant to the proper location, without the use of the rigid delivery catheter pod. ${ }^{7}$ This technique also allowed the use of a low profile sheath, facilitating entry into the narrow fistula without damaging or distorting adjacent vessels or myocardium. Optimal positioning of the device could also be monitored using retrograde repeat selective coronary injections.
The Amplatzer duct occluder is a new self expandable device made from a Nitinol wire mesh that was originally designed to occlude persistently patent arterial ducts with initially encouraging results both in animals and humans. ${ }^{910}$ This device has some important advantages including a small introducer sheath (6 F) allowing its application in small children as in our case 2; the ability to recapture or reposition if misplaced, and finally a high rate of closure. The practical technical requirements described above for the front loading double umbrella technique can also be extended to the Amplatzer implantation.

A previous case in the literature showing the application of this device to close a large coronary fistula from the circumflex artery to the right atrium was similar, although the patient was older. ${ }^{8}$

Owing to various coronary fistula morphologies, the interventionist must apply specialised techniques in a creative way. ${ }^{6}$ Umbrella implantation is a useful technique to close short and non-tortuous fistulae that drain into the right ventricle and are located near significant coronary branches. Similarly, implantation of the Amplatzer duct occluder appears to be particularly useful to close large, high flow fistulae that drain into the right ventricle or right atrium in the small children.

Dr CAC Pedra is supported by a grant provided by the "Dante Pazzanese" Institute of Cardiology and the "Adib Jatene" Foundation, Sao Paulo, Brazil.

1 Levin DC, Fellows KE, Abrams HL. Hemodynamically significant primary anomalies of the corornary arteries. Circulation 1978;58:25-34.

2 Liberthson RR, Sagar K, Berkoben JP, et al. Congenital coronary arteriovenous fistula: report of 13 patients, review of the literature and delineation of management. Circulation 1979;59:849-54

3 Reidy JF, Anjos RT, Qureshi SA, et al. Transcatheter embolization in the treatment of coronary artery fistulas. $\mathcal{F}$ Am Coll Cardiol 1991;18:187-92.

4 Perry SB, Rome J, Keane JF, et al. Transcatheter closure of coronary artery fistulas. F Am Coll Cardiol 1992;20:205-9.

5 Oureshi SA, Reidy JF, Alwi MB, et al. Use of interlocking detachable coils in embolization of coronary arteriovenous fistulas. Am f Cardiol 1996;78:110-13.

6 Wax DF, MaGee AG, Nykanen D, et al. Coil embolization of a coronary artery to pulmonary artery fistula from an antegrade approach. Cathet Cardiovasc Diagn 1997;42:68-9.

7 Nykanen DG, Hayes AM, Benson LN, et al. Transcatheter patent ductus arteriosus occlusion: application in the small child. 7 Am Coll Cardiol 1994;23:1666-70.

8 Hakim F, Madani A, Goussous Y, et al. Transcatheter closure of a large corornary arteriovenous fistula using the new Amplatzer duct occluder. Cathet Cardiovasc Diagn 1998;45:155-7.

9 Sharafundin MJ, Gu X, Titus JL, et al. Experimental evaluation of a new self-expanding patent ductus arteriosus occluder in a canine model. $\mathcal{F}$ Vasc Intervent Radiol 1996;7: 877-87.

10 Masura J, Walsh KP, Thanoupoulous B, et al. Catheter closure of moderate-large sized patent ductus arteriosus using he new Amplatzer duct occluder: immediate and short term result. F Am Coll Cardiol 1998;31:878-2. 